\title{
Hybrid Pulse Width Modulation Strategy for Wide Speed Range in IPMSM with Low Cost Drives
}

\author{
Han-woong Ahn*, Sung-chul Go ${ }^{\dagger}$ and Ju Lee*
}

\begin{abstract}
The control performance of hybrid PWM inverter using a phase current measurement is presented in this paper. The hybrid PWM technique consists of space vector pulse width modulation (SVPWM) and six-step voltage control operation. The SVPWM is performed to reduce the harmonic components in the low speed region, and the six-step modulation is applied to increase the maximum speed of the IPMSM in the high speed region. Therefore, it is possible to obtain a great performance in both the low speed range and high speed range. However, the six-step modulation cannot be completely implemented, since the inverter that includes the lag-shunt sensing method has an immeasurable current region. In this paper, a quasi-six-step modulation using a modified voltage vector is proposed. The validity and usefulness of the proposed PWM technique is verified by MATLAB/Simulink and experimental results.
\end{abstract}

Keywords: Hybrid pulse width modulation, Quasi-six-step modulation, Voltage utility maximization, Field weakening, Low cost IPMSM drive

\section{Introduction}

Interior permanent magnet synchronous motors (IPMSMs) have a number of advantages mainly in terms of weight and volume, which can be significantly reduced for a given output power. They also exhibit higher efficiency than other motors and have been widely used in various fields. The use of IPMSM in low-cost drives has also increased due to its applications in home appliance products. However, the low-cost drives have the disadvantage of having immeasurable current regions. Therefore, many studies have been conducted to develop a current sensing region. [1, 2] These algorithms, however, are not suitable for low-cost inverters because the implementation is highly complex.

In this paper, a hybrid pulse width modulation (PWM) of an IPMSM for low cost drives is proposed. The proposed modulation technique has greater voltage-utilization than others, and therefore, IPMSM can achieve a higher final speed. This paper also proposes quasi-six-step modulation.

\section{Basic Theorem of the Low Cost IPMSM Drivers}

This chapter covers the basic theorem to explain Hybrid PWM method proposed in this paper. It will explain about the field weakening control to increase speed above base

$\dagger$ Corresponding Author: Mechatronics R\&D Center, Samsung Electronics Co., Korea. (sc.go@samsung.com)

* Dept. of Electrical Engineering, Hanyang University, Korea. (zemlja@naver.com,julee@hanyang.ac.kr)

Received: October 12, 2015; Accepted: December 10, 2015 rpm and the characteristics of low cost inverter. Lastly, it will analyze maximum speed in accordance with the voltage modulation system of IPMSM.

\subsection{The field weakening control}

A field weakening control is performed to increase the speed range of IPMSM. IPMSM can be operated on high speed by flowing negative d-axis current through the field weakening control. Many techniques for field weakening control for IPMSM have been published [3]; in this paper, the field weakening control is performed by regulating the voltage loop as shown in Fig. 1. [4] At the less than base speed, the magnitude of the reference output voltage

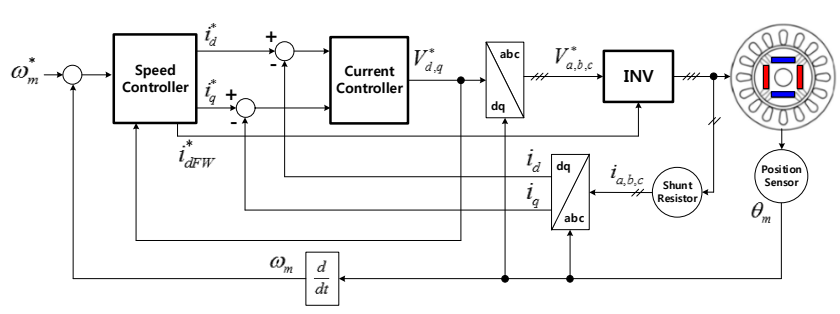

(a) The overall control system

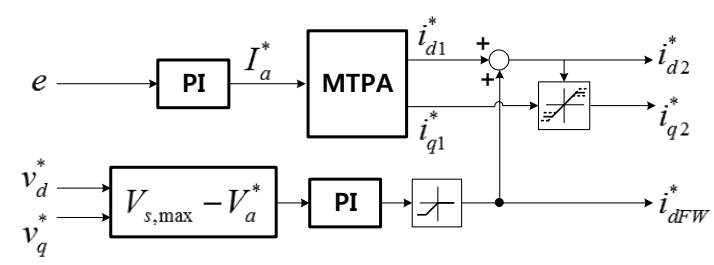

(b) The speed Controller with FW

Fig. 1. Block diagram of IPMSM drive system [4] 
is less than $V_{s, \max }$ and thus the field weakening current $i_{d F W}^{*}$ is zero. So, maximum torque-per-ampere control is performed. When the magnitude of the reference output voltage is larger than $V_{s, \max }, i_{d F W}^{*}$ is increase toward the negative direction for flux weakening operation. In this paper, the selection between the SVPWM and quasi-sixstep operation will be depended on the results from $i_{d F W}^{*}$. When $i_{d F W}^{*}$ is zero, SVPWM is conducted, and the quasisix-step operation is performed in the opposite case.

\subsection{The lag-shunt current SENSING method}

Three phase currents can be measured through one inexpensive shunt in the dc bus, or three phase shunt in the invert output sides or three shunt resistors in the low-side switches. Especially, the three shunt sensing technology, called a lag-shunt sensing method, is known for its great performance in cost-effectiveness. Therefore, it is widely used in low cost applications. [2] Fig. 2 shows a threephase inverter with lag-shunt resistors. However, lag-shunt sensing method cannot acquire phase currents in certain operating conditions. To measure the electric current of three-phase, electric current should flow into more than 2 shunt resistors, but electric current is not detected in case it flows into only 1 shunt resistor among 3 shunt resistors. Thus, an immeasurable current region occurs as in Fig. 3.

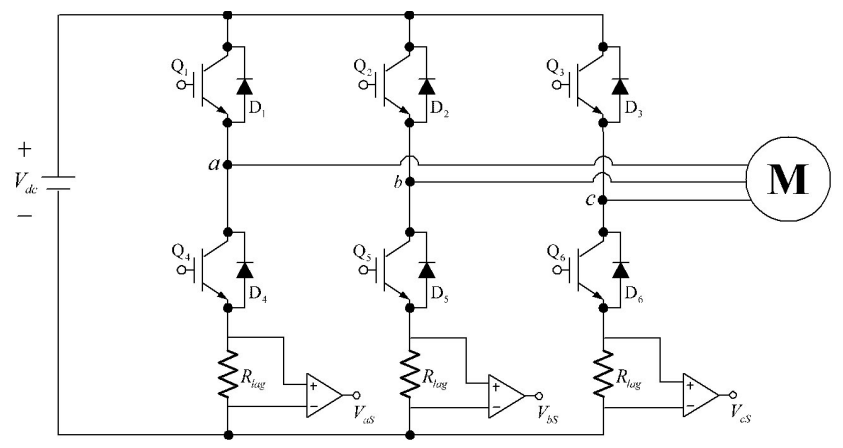

Fig. 2. A three-phase inverter driving IPMSMs with current sampling circuit

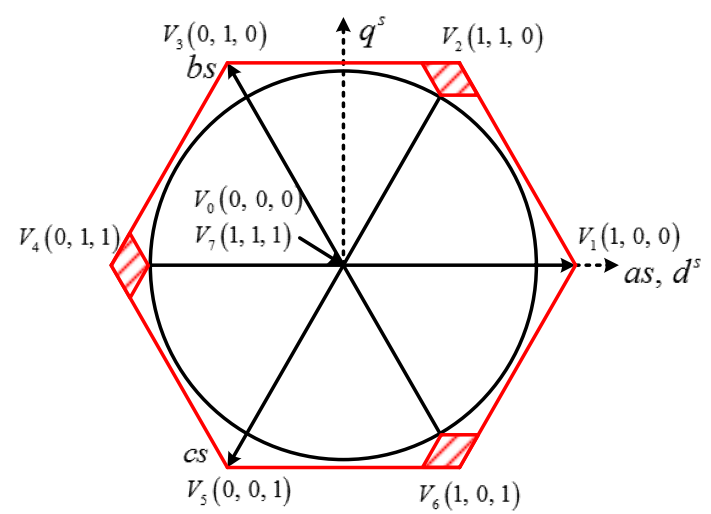

Fig. 3. Immeasurable current region in lag-shunt current sensing method.
The immeasurable current region can be determined by the minimum time it takes to sense the current $\mathrm{T}_{\mathrm{sm}} \cdot \mathrm{T}_{\mathrm{sm}}$ consists of inverter dead time, delay time of the current detection circuit and $\mathrm{A} / \mathrm{D}$ converter sampling time.

\subsection{The maximum speed of IPMSM}

The voltage equations of IPMSM in the synchronous d-q frame are given by using Clarke's and Park's transformations [5]

$$
\left[\begin{array}{c}
v_{d s}^{r} \\
v_{q s}^{r}
\end{array}\right]=\left[\begin{array}{cc}
R_{a} & -\omega L_{q} \\
\omega L_{d} & R_{a}
\end{array}\right]\left[\begin{array}{c}
i_{d s}^{r} \\
i_{q s}^{r}
\end{array}\right]+\left[\begin{array}{c}
0 \\
\omega_{e} \Psi_{a}
\end{array}\right]
$$

The terminal voltage supplied to the motor by the inverter is limited as follows

$$
V_{a}=\sqrt{v_{d s}^{r^{2}}+v_{q s}^{r 2}} \leq V_{a m}
$$

where $V_{a m}$ is the maximum output voltage of the inverter and depends on DC link voltage. It can be obtained according to the voltage modulation method.

$$
V_{a m(S V P W M)}=\frac{V_{d c}}{\sqrt{3}}, V_{a m(D P W M)}=\frac{V_{d c}}{\sqrt{3}}, \quad V_{a m(\text { six }-s t e p)}=\frac{2 V_{d c}}{\pi}
$$

Neglecting the voltage drop of the stator resistance, the voltage limit ellipse can be expressed by (1) and (2).

$$
\sqrt{\left(L_{d} i_{d s}^{r}+\Phi_{a}\right)^{2}+\left(L_{q} i_{q s}^{r}\right)^{2}}=\left(\frac{V_{a m}}{\omega}\right)
$$

The maximum speed of IPMSM can be obtained by the contact of current limit circles and voltage limit ellipse. It is expressed by substituting $i_{d s}^{r}=-I_{a m}$ and $i_{q s}^{r}=0$ into (4).

$$
\omega_{c}=\frac{V_{a m}}{\Phi_{a}-L_{d} I_{a m}}
$$

\section{Hybrid Pulse Width Modulation for Low Cost Drivers}

Because at least two low-side switches are required to measure the three phase current, discontinuous pulse width modulation (DPWM) is most commonly applied to low cost drives. It is possible to increase the speed limit by utilizing six-step modulation. However, it causes noise and vibration, especially in the low speed range including many harmonics. [6] Therefore, a low modulation index will lower harmonic content by driving the motor in SVPWM and increase the speed range by changing into a six-step modulation in the field weakening area. 


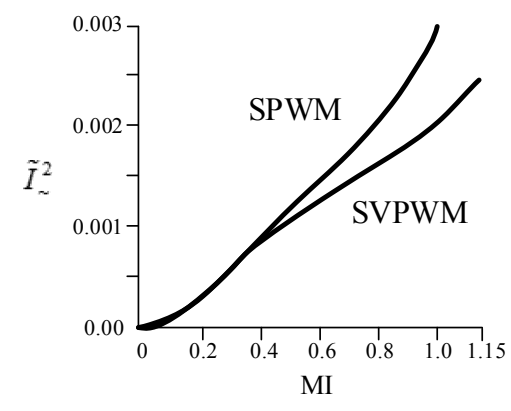

(a) Square of rms harmonic current

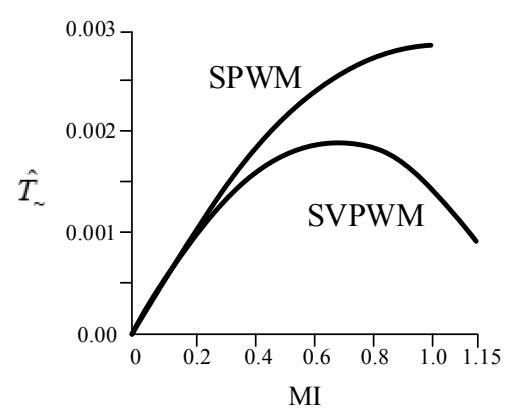

(b) Peak values of torque harmonics

Fig. 4. Characteristics of SPWM and SVPWM [7]

\subsection{SVPWM at low modulation index}

In the low-speed region that has a low voltage modulation index, SVPWM is used. Among other PWM techniques, SVPWM contains the least harmonic components and has a wide linear modulation interval. [7] The harmonics characteristics of SVPWM are compared with those of SPWM in Fig. 4; SVPWM, therefore, operates below the base speed. It should be noted that SVPWM is difficult to implement because the on-time of the switches needs to be operated in a fixed sequence. However, this problem can be fixed simply by using the offset voltage, using the following equation.

$$
V_{\text {offset }}=-\frac{V_{\max }+V_{\min }}{2}
$$

\subsection{Six-step modulation at high modulation index}

When the voltage of power supply goes higher than $V_{d c} / \sqrt{3}$, the voltage limit, while driving the motor in SVPWM, it will go over the linear modulation section. As a result, field weakening control is performed to widen the speed range. However, a higher output can be obtained if the motor is driven in six-step modulation in the field weakening area because voltage use rates increases by $10.25 \%$ compared to SVPWM. Therefore, the output of motor can be enhanced by driving it in six-step modulation in the area above base rpm. [8]

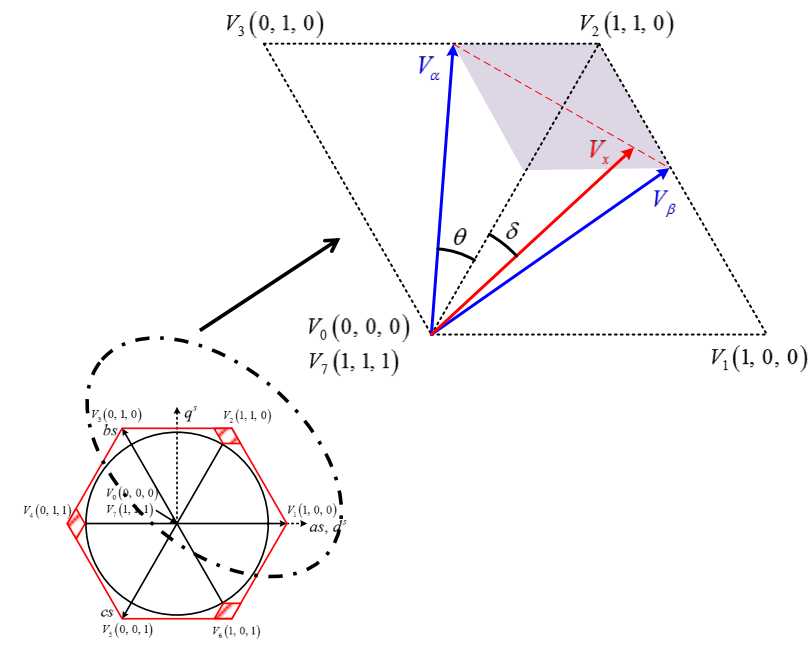

Fig. 5. The modified voltage vectors of $V_{2}$

\subsection{Quasi-six-step modulation for the low cost drives}

Since the lag-shunt sensing inverter has an immeasurable region, it is impossible to induce the voltage vector $V_{2}$, $\mathrm{V}_{4}$, and $\mathrm{V}_{6}$; the six-step modulation, therefore, cannot be performed. However, by modifying the voltage vector, nearly the same control as the square wave can be achieved. Fig. 5 enlarges the surroundings of voltage vector $V_{2}$ among the immeasurable current region. In Fig. 5, the colored portion indicates the immeasurable region. Among voltage vectors that can be induced instead of $V_{2}$, the ones with the highest magnitude are defined as $\mathrm{V}_{\alpha}$ and $\mathrm{V}_{\beta}$. The magnitude of $V_{\alpha}$ and $V_{\beta}$ is represented as follow

$$
V_{\alpha m}=V_{\beta m}=\frac{V_{d c}}{2} \sqrt{T_{s m}^{2}-T_{s m}+1}
$$

The larger the value of voltage vector, the more operating high output. Depending on the load conditions, the motor can show better characteristics on a certain location between $V_{\alpha}$ and $V_{\beta}$. Thus, by using $V_{\alpha}$ and $V_{\beta}$ vector, it can operate adjusting $\mathrm{V}_{\mathrm{x}}$ vector in accordance with the load condition. The magnitude of $\mathrm{V}_{\mathrm{x}}$ vector is obtained as

$$
V_{x m}=\frac{V_{d c}}{4}\left(2-T_{s m}\right) \cdot \frac{1}{\cos \delta}
$$

The speed limit can be increased by applying the modified voltage vectors $\mathrm{V}_{\alpha}, \mathrm{V}_{\beta}$, and $\mathrm{V}_{\mathrm{x}}$ instead of $\mathrm{V}_{2}$ for six-step modulation in the lag-shunt sensing inverter.

\section{Simulation and Experimental Results}

The simulation and experiment were implemented on the 750W IPMSM servomotor. The specifications of the 
Table 1. Specifications of IPMSM

\begin{tabular}{c|c|c}
\hline Parameter & Value & Unit \\
\hline $\mathrm{N}_{\mathrm{p}}$ & 4 & \\
\hline $\mathrm{V}_{\mathrm{dc}}$ & 50 & $\mathrm{~V}$ \\
\hline $\mathrm{I}_{\mathrm{am}}$ & 4 & $\mathrm{~A}$ \\
\hline $\mathrm{R}_{\mathrm{a}}$ & 0.82 & $\mathrm{Ohm}$ \\
\hline $\mathrm{T}_{\max }$ & 2.28 & $\mathrm{Nm}$ \\
\hline$\Phi_{\mathrm{a}}$ & 0.098 & $\mathrm{~Wb}$ \\
\hline $\mathrm{L}_{\mathrm{d}}$ & 14 & $\mathrm{mH}$ \\
\hline $\mathrm{L}_{\mathrm{q}}$ & 18 & $\mathrm{mH}$ \\
\hline
\end{tabular}

IPMSM are presented in Table 1. The base speed of the test motor is 1070rpm. Applying the Eq. (5) for the test motor, the maximum speed is about 3300 rpm when operated sixstep modulation. To analyze the maximum speed with voltage modulation methods, 3500rpm which is more than theoretical value was given to the reference speed.

\subsection{Simulation results}

In order to verify the performance of the proposed algorithm, the simulation is performed by MATLAB / Simulink. A simulation model that consists of the IPMSM is built in MATLAB. Fig. 6 (a) and (b) demonstrate that the final speed is similar because SVPWM and DPWM have the same voltage utilization rate. Through Fig. 6 (c), it could be confirmed that the speed increased by $10.27 \%$ compared to DPWM as six-step modulation was applied in high modulation index. Fig. 6 (d), (e), and (f) show the results of quasi-six-step modulation, representing $\delta=+\theta,-\theta$, 0 respectively. While the speed decreased compared to Fig. 6 (c), it increased by $9.0 \%$ compared to SVPWM and DPWM. In Fig. 6 (d), the speed was the highest because the motor is R-L load.

\subsection{Experimental result}

The hybrid PWM algorithm is processed in a control board

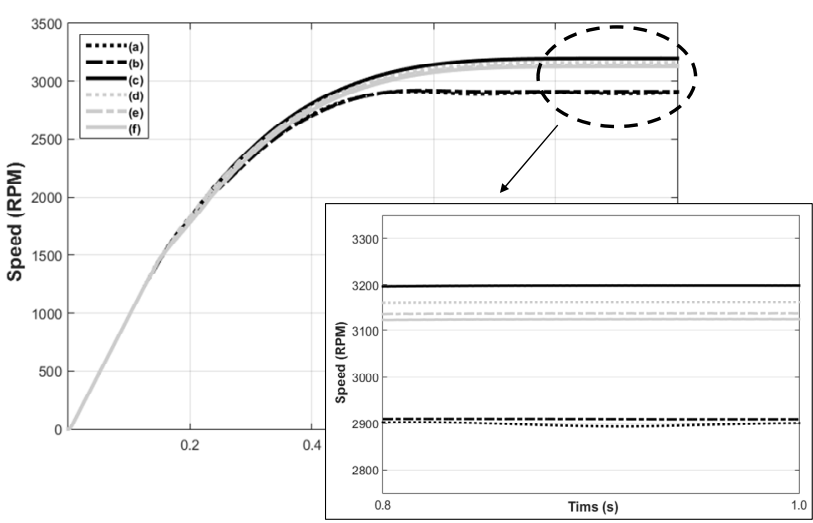

(a) SVPWM (b) DPWM (c) Six-Step Modulation in FW; (d) QuasiSix-Step Modulation by $\mathrm{V}_{\alpha}$; (e) Quasi-Six-Step Modulation by $\mathrm{V}_{\beta}$; (f) Quasi-Six-Step Modulation by $\mathrm{V}_{\mathrm{x}}\left(\delta=0^{\circ}\right)$

Fig. 6. The simulation final speed $\left(\omega_{\mathrm{m}}{ }^{*}=3,500 \mathrm{rpm}\right)$

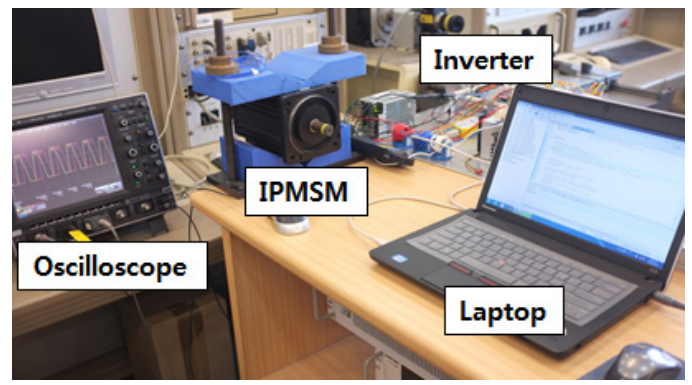

Fig. 7. Experimental test setup

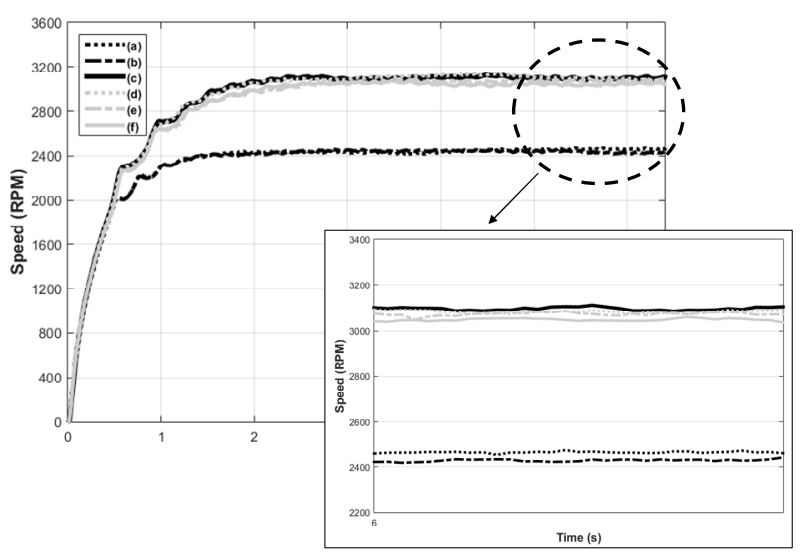

(a) SVPWM (b) DPWM (c) Six-Step Modulation in FW ; (d) QuasiSix-Step Modulation by $\mathrm{V}_{\alpha}$; (e) Quasi-Six-Step Modulation by $\mathrm{V}_{\beta}$; (f) Quasi-Six-Step Modulation by $\mathrm{V}_{\mathrm{x}}\left(\delta=0^{\circ}\right)$

Fig. 8. The experimental final speed $\left(\omega_{\mathrm{m}}{ }^{*}=3,500 \mathrm{rpm}\right)$

Table 2. CPSR of the test motor using different PWM methods

\begin{tabular}{c|c|c|c|c}
\hline \multirow{2}{*}{ PWM Method } & \multicolumn{2}{|c|}{ Simulation } & \multicolumn{2}{c}{ Experiment } \\
\cline { 2 - 5 } & $\begin{array}{c}\text { Final Speed } \\
{[\mathrm{rpm}]}\end{array}$ & CPSR & $\begin{array}{c}\text { Final Speed } \\
{[\mathrm{rpm}]}\end{array}$ & CPSR \\
\hline SVPWM & 2900 & 2.71 & 2462 & 2.30 \\
\hline DPWM & 2900 & 2.71 & 2440 & 2.28 \\
\hline Hybrid PWM & 3198 & 2.99 & 3102 & 2.90 \\
\hline $\mathrm{V}_{\alpha}$ & 3161 & 2.95 & 3074 & 2.87 \\
\hline $\mathrm{V}_{\beta}$ & 3137 & 2.93 & 3070 & 2.87 \\
\hline $\mathrm{V}_{\mathrm{x}}\left(\delta=0^{\circ}\right)$ & 3125 & 2.92 & 3060 & 2.86 \\
\hline
\end{tabular}

based on the Digital Signal Processor TMS320F28335. The modulation methods are carried out by triangular carrier comparison using a carrier frequency of $10 \mathrm{kHz}$, and the minimum time for the current sensing $\mathrm{T}_{\mathrm{sm}}$ is $8 \mu \mathrm{s}$. The experimental test setup is shown in Fig. 7.

Fig. 8 (a) and (b) show the final speed of SVPWM and DPWM. As in the simulation, both have similar values. Fig. 8 (c) shows the result of six-step modulation in field weakening and increased by $25.36 \%$ compared to Fig. 8 (a) and (b). Fig. 8 (d) $\sim$ (f) shows the use of modified voltage vectors applied in low cost inverter, and while the speed decreased compared to Fig. 6 (c) it increased by $23.95 \%$ compared to Fig. 6 (a) and (b).

Table 2 shows constant power speed ratio (CPSR) of the test motor depending on PWM Methods. [9] 


\section{Conclusion}

In this paper, the voltage utility maximization algorithm based on a lag-shunt sensing method is proposed. The proposed hybrid PWM strategy is verified with a servomotor comparing DPWM. And quasi-six-step is performed by applying the modified voltage vectors, since the lag-shunt sensing inverter has an immeasurable current region. The usefulness and effectiveness of the algorithm is confirmed by MATLAB/Simulink, and the validity of the voltage utility maximization algorithm is verified by the servomotor.

\section{Acknowledgements}

This work was supported by the National Research Foundation of Korea (NRF) grant funded by the Korea government (MSIP) (No.2013R1A2A1A01015171)

\section{References}

[1] Hyunbae Kim, Sungmo Yi, Namsu Kim, Robert D. Lorenz "Using Low Resolution Position Sensors in Bumpless Position/Speed Estimation Methods for Low Cost PMSM Drives", IEEE IAS Annual Meeting 2005, Vol. 5, pp. 2518-2525, Oct. 2005.

[2] Byung-Geuk Cho, Jung-Ik Ha, Seung-Ki Sul, "Analysis of the Phase Current Measurement Boundary of Three Shunt Sensing PWM Inverters and an Expansion Method", Journal of Power Electronics, Vol. 13, No. 2, pp. 232-242, Mar. 2013.

[3] T. M. Jahns, "Flux-weakening Regime Operation of an Interior Permanent Magnet Synchronous Motor Drive", IEEE Trans. Ind. Appl, Vol. IA-22, No. 4, pp. 738-747, Jul./Aug. 1987.

[4] Jang-Mok Kim, Seung-Ki Sul, "Speed Control of Interior Permanent Magnet Synchronous Motor Drive for the Flux Weakening Operation", IEEE Trans. Ind. Appl, Vol. 33, No. 1, pp. 43-48, Jan./Feb. 1997.

[5] Seung-Joo Kim, Hyung-Woo Lee, Kwang-Soo Kim, Jae-Nam Bae, Jong-Bin Im, Cherl-Jin Kim, and Ju Lee, "Torque Ripple Improvement for Interior Permanent Magnet Synchronous Motor Considering Parameters With Magnetic Saturation", IEEE Trans. Magn., Vol. 45, No. 10, pp. 4720-4723, Oct. 2009.

[6] Ahmet M. Hava, Russel J. Kerkman, Thomas A. Lipo, "A High Performance Generalized Discontinuous PWM Algorithm”, IEEE Trans. Ind. Appl, Vol. 34, No. 5, pp. 1059-1071, Sep./Oct. 1998.

[7] H. W. Van Der Broeck, H. C. Skedelny, and G. V. Stanke, "Analysis and realization of a pulsewidth modulator based on voltage space vectors", IEEE Trans. Ind. Appl, Vol. 24, No. 1, Jan./Feb. 1988, pp.
142-150.

[8] Yong-Cheol Kwon, Sungmin Kim, Seung-Ki Sul, "Six-Step Operation of PMSM with Instantaneous Current Control”, IEEE Trans. Ind. Appl, Vol. 50, No. 4, pp. 2614-2625, Jul./Aug. 2014.

[9] G. R. Slemon, "Achieving Constant Power Speed Range for PM drives", IEEE Trans. Ind. Appl, Vol. 31, No. 2, pp. 368-372, Mar./Apr. 1995.

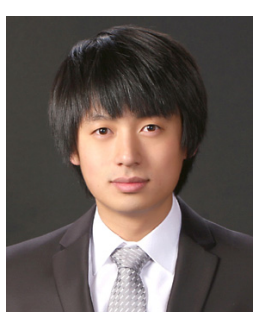

Han-Woong Ahn He received his B.S. and M.S. degrees in Electrical Engineering from Hanyang University, Seoul, Korea in 2010 and 2012, respectively. Since 2012, he has been pursuing the Ph.D. degree at the Department of Electrical Engineering, Hanyang University. His research interests include design, analysis, testing and control of motor/generator; power conversion systems; and applications of motor drive.

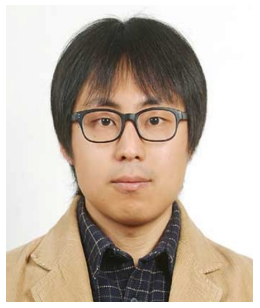

Sung-Chul Go He received his B.S., M.S. and Ph.D. degrees in Electrical Engineering from Hanyang University, Seoul, Korea in 2004, 2006 and 2010 respectively. He is now working in Samsung Electronics Co. His research interests include design, analysis, testing and control of motor/generator; power conversion systems; and applications of motor drive, such as electric vehicles, high-speed maglev train and renewable energy systems.

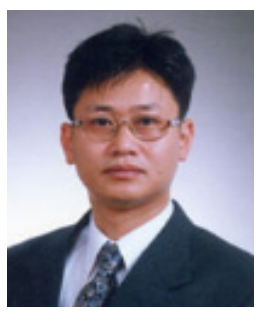

Ju Lee He received his M.S. degree from Hanyang University, Seoul, South Korea, in 1988, and his Ph.D. from Kyusyu University, Japan in 1997, both in Electrical Engineering, He joined Hanyang University in September, 1997 and is currently a Professor of the Division of Electrical and Biomedical Engineering. His main research interests include electric machinery and its drives, electromagnetic field analysis, new transformation systems such as hybrid electric vehicles (HEV), and high-speed electric trains and standardization. $\mathrm{He}$ is a member of the IEEE Industry Applications Society, Magnetics Society, and Power Electronics Society. 